\title{
Scientific evidence for the treatment of children with irritable bowel syndrome
}

Paolo Quitadamo ${ }^{1}$, Sara Isoldi ${ }^{2}$, Saverio Mallardo ${ }^{2}$, Letizia Zenzeri ${ }^{3}$, Giovanni Di Nardo ${ }^{4}$

1 Department of Pediatrics, A.O.R.N. Santobono-Pausilipon, Naples, Italy

2 Maternal and Child Health Department, Sapienza - University of Rome, Santa Maria Goretti Hospital, Polo Pontino, Latina, Italy

3 Pediatric Emergency Unit, Santobono-Pausilipon Children's Hospital, Naples, Italy

4 Chair of Pediatrics, Pediatric Gastroenterology and Endoscopy Unit, NESMOS Department, FacultySchool of Medicine and Psychology,

Sapienza University of Rome,

Sant'Andrea University Hospital, Rome, Italy

Funding Source: None to declare

Financial Disclosure: The authors have no financial relationships relevant to this article to disclose

Conflict of Interest: The authors have no conflicts of interest to disclose

Word count: 4287

Address all correspondence to: Paolo Quitadamo

Department of Pediatrics

A.O.R.N. Santobono-Pausilipon

Via Mario Fiore 6

80129 - Naples, Italy

e-mail: paoloquitadamo@yahoo.it 


\begin{abstract}
Irritable bowel syndrome (IBS) is one of the most common functional gastro-intestinal disorders which significantly impacts the quality of life of affected children. Abdominal pain improved by defecation, associated with a change in stool form and frequency, represents its specific clinical marker. Even if a number of potential patho-physiological mechanisms have been described, the exact underlying etiology of IBS is so far unclear. Likewise, no optimal treatment has ever been found neither for adult nor for pediatric patients. Current therapeutic options include drugs, dietary interventions and biopsychosocial therapies. The present review aims at evaluating the scientific evidence supporting the efficacy of these treatments for children with IBS.
\end{abstract}




\section{Introduction}

Irritable bowel syndrome (IBS) is one of the most common pediatric functional gastrointestinal disorders (FGIDs), affecting $0.2 \%$ of children seen by primary care pediatricians and $22-45 \%$ of those presenting to tertiary care centers. Although IBS is not a life-threatening condition, it impacts quality of life similarly to organic digestive diseases, particularly in most severe cases [1-5]. IBS is characterized by abdominal pain that is improved by defecation and whose onset is associated with a change in stool form and/or frequency and is not explained by structural or biochemical abnormalities. Despite growing interest and research into IBS over the last 30 years, the underlying cause of this condition remains unknown. We can suppose that it is actually unlikely that a single entity could be responsible for the diverse presentations of such a heterogeneous disorder. IBS is almost certainly a multi-factorial illness with particular factors being of paramount importance in certain individuals. These include: altered bowel motility, visceral hypersensitivity, central processing, genetic factors, psychological factors, inflammation, and dietary factors.

Even from a clinical perspective, IBS is currently still a challenging condition for clinicians. Unlike many other gastrointestinal disorders, IBS has major challenges in terms of diagnosis and management. In the absence of detectable biomarkers, IBS is a purely symptom-based diagnosis. Although international management guidelines recommend that clinicians should make a positive diagnosis of IBS without resorting to invasive investigation, some individuals end up undergoing repeated tests in order to exclude an underlying organic cause for their symptoms [1]. Following IBS diagnosis, no single optimal treatment has ever been found neither for adult nor for pediatric patients. Current therapeutic options include drugs, dietary interventions and biopsychosocial therapies. The present review aims at evaluating the scientific evidence supporting the efficacy of these treatments for children with IBS.

\section{Pathogenesis}

Several studies have been carried out in adults and children with IBS and a large number of possible pathophysiological mechanisms have been suggested. Nevertheless, to date no single clear etiopathogenesis has been demonstrated for IBS. The debate is currently about the different burden of hereditary and 
environmental factors and the possible interaction between them. Studies both in children and adults have suggested different mechanisms which may contribute to the development of IBS, including infection, inflammation, visceral hypersensitivity, allergy and disordered gut motility [6].

The prevailing proposed models agree to consider IBS as a brain-gut disorder. It is postulated that a state of dysregulation occurs within the enteric and the central nervous systems in patients with IBS and this results in alteration in sensation, motility, and possibly immune system dysfunction [6]. The primary origin of these bidirectional brain-gut interactions is not known, having both top-down and bottom-up models been investigated $[7,8]$. The autonomic nervous system has been considered to be one of the main communicators between the brain and the gut in both top-down and bottom-up models of IBS pathogenesis. However, so far very few studies have been conducted to assess the autonomic nervous system in IBS and its exact role in generation of symptoms is not clear [9].

Recent scientific evidence supports the assumption of IBS as a low grade inflammatory disorder [10]. Indeed, both histological specimens obtained at endoscopy and serological cytokine studies have demonstrated low grade inflammation in IBS [11], in which mast cells (MC) appear to play a particularly important role [1217]. An increased number of active degranulating MCs has been reported in patients with IBS compared to that in healthy controls as well as a significant correlation between the density of intestinal MCs and the severity of abdominal pain $[15,18,19]$. Moreover, children with IBS have been reported to have an increased GI permeability, even if no correlation was found between its degree and pain related symptoms [20].

The role of the intestinal microbiota for IBS development has also been investigated. Specific microbiome signatures have been associated with pediatric IBS, corroborating previous data obtained in studies of adult patients with IBS [21].

Finally, as there is a strong familial trend noted in IBS, there has been an ongoing interest in finding a genetic link in IBS. So far, a positive association between IBS and interleukin-10 polymorphism has been reported [22].

\section{Peppermint oil}

The main component of peppermint oil (PO) is menthol, which exerts an antispasmodic action acting as a calcium antagonist and resulting in anti-flatulent action, the exact mechanism of which remains currently 
unexplained. Most of scientific evidence on PO concerns the adult population. The first report on PO use in IBS dates back to 1979, when Rees et al blindly administered PO capsules to 18 patients with IBS symptoms [23]. Patients experienced more symptom-free days and fewer severe symptoms on PO, yet the differences from placebo were not statistically significant. Afterwards a series of randomized controlled trials showed that PO was safe and efficacious as a symptomatic remedy [24]. Average response rates were 58\% (range 39-79\%) compared to $29 \%$ (range 10-52\%) for placebo. Adverse events reported with PO were generally mild and transient and included heartburn and anal/perianal burning or discomfort.

The only study ever carried out in children was a randomized clinical trial by Kline RM et al dated 2001 [25]. Forty-two children over 8 years old with IBS were blindly given pH-dependent, enteric-coated peppermint oil capsules (187 mg per capsule) or placebo. Patients weighing more than $45 \mathrm{~kg}$ received 2 peppermint oil or placebo capsules 3 times a day. The smaller children, who weighed between $30 \mathrm{~kg}$ and $45 \mathrm{~kg}$, received 1 capsule 3 times a day. At the conclusion of the 2 -week trial, 75\% of children receiving peppermint oil had reduced severity of abdominal pain compared with 19\% receiving placebo. Other associated symptoms, such as heartburn, gas, urgency of stools, belching, stool pattern, or stool consistency were not altered. No adverse events were reported.

\section{Antispasmodic agents}

Antispasmodic agents are frequently administered as first-choice treatment in pediatric population affected by IBS [26]. Indeed, it has been demonstrated that this class of drugs acts especially on IBS with diarrhea-predominant IBS [27]. Antispasmodic agents are classified as follows:

- Antimuscarinic agents/anticholinergics drugs 
Hyoscyamine and dicyclomine act on smooth muscle of the intestinal tract and their efficacy has been assessed only in adult population [28]. However, these drugs present several side effects such as tachycardia, constipation, dry mouth and urine retention [29].

- Peripheral opiate agonists

Trimebutine maleate acts on the peripheral opiate receptors [delta, mu and kappa] as antinociceptive drug. Furthermore, it acts also as prokinetic agent through the release of motilin, vasoactive intestinal peptide, gastrin and glucagon [30]. Therefore, trimebutine promotes gastro-intestinal motility and modulates visceral sensitivity, reducing reflexes secondary to the distension of the bowel [30-32]. A randomized controlled trial reported the effectiveness of trimebutine maleate on 78 children [aged 4-18 years] with IBS. Authors compared two groups (treated and not) in term of clinical improvement, and they showed a recovery in $94.9 \%$ of treated versus $20.5 \%$ of untreated patients [33]. In adults with IBS, the efficacy of trimebutine is controversial $[34,35,26]$.

- Smooth muscle relaxants

Mebeverine is a beta-phenylethylamine derivative which produce anti-peristaltic effects on the bowel. However, studies conducted on adult population failed to report a statistically significant efficacy in the treatment of IBS when compared to placebo $[36,27,28]$. Likewise, no statistically significant effect of mebeverine versus placebo has been demonstrated in children [37]. Similar results have been reported in a randomized clinical trial comparing mebeverine and trimebutine in IBS patients (15-60 years of age) in terms of symptoms improvement [38]. To our knowledges, this is the only study comparing two antispasmodic treatment and no data are available in pediatrics [26]. Sides effects reported with mebeverine usage are dry mouth, drowsiness and agitation. Since these occur in a very small percentage of patients, this drug has generally been considered well-tolerated by patients [39].

In conclusion, a Cochrane meta-analysis and an evidence-based review conducted on adult populations stated the possible efficacy of antispasmodics in IBS patients [40, 41]. Since very few studies are available 
about antispasmodics use in children with IBS, this class of drugs should not be recommended as primary treatment in pediatric age [26].

\section{Anti-diarrheal agents}

This group of therapeutics agents have a limited role but could be tried in IBS children with predominant diarrhea (IBS-D) [27]. This drug class includes opiates agonists, 5-hydroxytryptamine (5-HT3) receptor antagonists and bile acid sequestrants.

Opiates agonists acts on opioid receptors, which are localized throughout the gastrointestinal tract. Loperamide is a synthetic agent that acts on $\mu$ receptors for opioids inhibiting the release of acetylcholine with consequently reduction of intestinal peristalsis and intestinal secretion [42]. Loperamide is rapidly absorbed, metabolized in the liver and excreted in the bile, therefore systemic side effects are negligible. Moreover, no central side effects are reported because of its failure to pass the blood-brain barrier. Adult studies reported its usefulness in treating diarrhea in patients with IBS but no benefit has been reported on pain relief [43]. No evidence is available regarding its usefulness in children with IBS.

Eluxadoline is a novel drug acting on opioid receptors, and in particular on $\delta$-, $x$-, and $\mu$-opioid receptors. It has been recently approved by the FDA for treatment of diarrhea in IBS adults. However, side effects have been reported, such as sphincter of Oddi spasm and pancreatitis [44], thus it should be discouraged in patients with history of pancreas disorder, gallbladder disorder and severe liver impairment. A phase 2, randomized, double-blind, placebo-controlled study is ongoing in pediatric patients with IBS-D, however results are not yet available.

Limited evidences are available regarding the use of serotonin-based agents such as alosetron and cilansetron in adults with IBS-D. They act inhibiting 5-HT3 receptors and reducing visceral sensation and slowing the colonic transit $[45,46]$. However, no data are available regarding their use in children and severe side effects have been reported, such as ischemic colitis and perforations. For this reason, alosetron is currently available only in few countries with a very limited indication, and cilansetron was never advertised [47]. 
Bile acid sequestrants such as cholestyramine, colestipol and colesevelam are generally used to treat adults with bile acid diarrhea. Nevertheless, a higher proportion of primary bile acids have been found in stools of patients with IBS-D, probably due to the accelerated transit time that reduce the capability of microbiota to convert them [48]. Therefore these agents have been recently evaluated in several open label studies that demonstrated their effectiveness in adult patients with IBS-D, particularly in those with proved bile acid malabsorption $[49,50]$. However, patient compliance is generally affected poor palatability [51]. To our knowledge, no clinical trials are currently available in children.

\section{Antibiotics}

The usefulness of rifaximin in adult patients with IBS laid the foundation for a role of the gut microbiome in the pathogenesis of this disease [42]. Rifaximin is a wide spectrum, poorly absorbed oral antibiotic acting as an inhibitor of bacterial RNA synthesis. Adult studies support its use expecially in non constipation-type IBS [52, 53]. It is commonly used in patients with small intestine bacterial overgrowth (SIBO) $[54,55]$; nevertheless, the TARGET study demonstrated its efficacy also in adult patients with IBS without SIBO [52]. Data on the efficacy of rifaximin in paediatrics are scarse. It has been demonstrated that SIBO is highly prevalent in children with IBS, and in particular in about $65 \%$ of them in a report [56]. An open label trial including 50 children with IBS confirmed this association, showing a prevalence of SIBO in this population in the majority [66\%] [57]. In this study SIBO was evaluated by using lactulose breath test, and patients with a positive test were started on rifaximine for 7 days. Interestingly, only patients with a normalization of the test showed an improvement of symptoms. Unfortunaltely, patients with normal lactulose breath test at baseline remained untreated, therefore the abscence of a control group and placebo treatment make this study only a preliminar evaluation, needing a randomized double-blind placebo-controlled interventional trial for confirmation. Another clinical trial is available evaluating the efficacy of rifaximin in children with functional abdominal pain [58], but only 55\% of the sample met the diagnostic criteria for IBS. All the children underwent lactulose breath test, showing an abnormal result in $95 \%$ of those with IBS. However, no significant improvement of symptoms was recorded after 10 days of therapy and without normalization of the lactulose breath test, suggesting that probably SIBO had limited implication in the 
pathophysiology. Further prospective clinical trials with a larger cohort are needed in children to assess the usefulness of antibiotics in IBS.

\section{Amitriptyline}

Amitriptyline (AMI) is a tricyclic antidepressant (TCA) that can be considered as possible treatment option for IBS. In adult it has been demonstrated as an effective drug in improvement feelings of well-being and abdominal pain. Indeed, AMI is effective in increasing central pain tolerance (peripheral anti-neuropathic effects), relieving diarrhea (anticholinergic effects) and improving GI motility [27]. It has been hypothesized that AMI inhibits currents of voltage-gated sodium channels leading to a reduction of visceral sensitivity [59, 60]. Others potentials mechanism of action of AMI as analgesic could probably be related to its effect on the endogenous opioids pain modulation system, on the serotonergic and adenosine pathways and on the modulation of the NMDA (N-methyl-D-aspartate) receptor [61-63]. Moreover, two meta-analysis on adult population demonstrated its effectiveness in improving IBS symptoms compared to placebo [64, 65]. Nevertheless, the exact mechanisms of action of TCAs is still unknown because they have different targets through which they carry out antinociceptive effects.

In pediatric population, the benefits of TCAs are more controversial and evidence in literature are very scarce. Bahar et al, in a randomized double-blind placebo-controlled trial, evaluated 33 patients [aged 12-18 years old] with IBS treated amitriptyline. They showed an improvement of quality of life, IBS-related diarrhea and abdominal pain at 10 and at 13 weeks of treatment compared with patients treated with placebo [66].

On the other hand, Saps et al found no significant difference in term of IBS-associated symptoms relief between amitriptyline and placebo treatment. Among 83 patients enrolled (40 placebo, 43 drug), 63\% of those on amitriptyline exhibited an overall symptoms improvement after 4 weeks of treatment, compared with 57.5\% in the placebo arm $(\mathrm{p}=0.63)$. However, a significant reduction of anxiety scores was recorded among patients treated with AMI $(\mathrm{p}<0,0001)$ [67]. In a retrospective study, Teitelbaum et al observed an $84.4 \%$ response rate to AMI in IBS pediatric patients, with an average duration of response of 12.93 months (range $2-45$ months). However, considered the absence of a control group, the potential placebo effect was not evaluated [68]. AMI treatment has been associated with QTc prolongation, therefore screening electrocardiogram is recommended 
[69]. In addition, an increased risk of suicidal ideation especially in adolescents and children major psychiatric comorbidities has been associated to TCAs [70]. In conclusion, not enough evidence suggest a better efficacy of AMI compared to placebo in IBS pediatric patients [71].

\section{Tegaserod}

Tegaserod is a partial selective 5-hydroxytryptamine (serotonin) type 4 receptor agonist that has been evaluated as possible treatment for adult and pediatric patients with IBS, especially in case of constipationpredominant subtype (IBS-C) [72-74]. Indeed, it has been reported that tegaserod is effective in accelerating intestinal motility in animal models by stimulating peristaltic reflex [75]. By the same way, it has been observed that this drug exerts analgesic effect by reducing visceral hypersensitivity secondary to bowel distension [76, 77]. Since 2001, tegaserod has proven to be effective in adult patients with IBS [21, 78]. According to a Cochrane review analysing the efficacy of tegaserod versus placebo, other interventions or no treatment among IBS patients, tegaserod showed to be effective especially in patients with IBS-C [79]. Moreover, tegaserod showed an efficacy in relieving gastrointestinal symptoms [pain, stool consistency, bloating] and improving quality of life in women with IBS [80]. Nonetheless, this drug as not been licensed in many countries because of the related risk of cardiovascular ischemic events [81]. In 2019, the Food and Drug Administraion and the Gastrointestinal Drug Advisory Committee declared that evidence about its cardiovascular toxicity was weak and suggested to avoid its use only in patients with transient ischaemic attacks, stroke, angina or myocardial infarction [82].

Currently, only a limited number of trials have been published in pediatric population, hence no real evidence are available regarding the efficacy and safety of tegaserod for IBS treatment in children [83]. A retrospective study evaluated the usefulness of tegaserod among 72 children with functional gastrointestinal disorders. The Authors observed an overall improvement of constipation and abdominal pain in the majority of patients (64-71\%) after a 1-year follow-up. However, the results of this study were limited by the small sample size, the heterogenicity of functional gastrointestinal disorders considered and the presence of side effects in about $32 \%$ of patients (especially diarrea). Therefore, the Authors concluded that tegaserod could 
represent an adjuvant/alternative treatment in a selected group of patients in which symptomatology persists despite conventional treatments [84].

\section{Probiotics}

Microbiota is thought to play a pivotal role in the gut homeostasis, ensuring the microbial balance through metabolic competition with pathogens, and regulating the mucosal barrier and the intestinal inflammatory response [85]. Recent studies suggested that dysbiosis may contribute in generating visceral hypersensitivity, dysmotility and abnormal colonic fermentation [29, 86-90]. An alteration of fecal microbiota has been demonstrated in IBS, both in adults [90-92] and in children [93], suggesting a diagnostic potential of specific microbial fingerprints in differentiating it from other gastrointestinal condition, and a new therapeutic target, in the era of the precision medicine. Several formulations of probiotics are available, with different concentrations, but the heterogeneity of the available studies makes it difficult to make conclusions about the real efficacy of them. A recent meta-analysis on the efficacy of probiotics in IBS showed that probiotics are effective in adult population even if the most active species, strain and dosing are yet to be assessed [94].

Data on children and adolescents are equally scarce and conflicting. A study on 203 children aged 4 to 18 years treated with the natural intestinal bacterium E. coli reported a significant improvement of IBS symptoms (abdominal pain, stool frequency, bloating, urge to defecate) [95]. Moreover, VSL\#3 (a mixture of 8 different strains at a concentration of 450 billion per sachet: Bifidobacterium breve, B longum, B infantis, Lactobacillus acidophilus, L plantarum, L casei, L bulgaris, and Streptococcus thermophilus Lactobacillus GG) was demonstrated to be safe and more effective than placebo for IBS sympotms. A sample of 59 children aged 4-18 years were randomized to receive either VSL\#3 or a placebo for 6 weeks and probiotics were found superior to placebo in reliefing symptoms [abdominal pain/discomfort, abdominal bloating/gassiness] and in improving family assessment of life disruption [96]. The same year, a randomized double-blind, placebocontrolled trial on Lactobacillus rhamnosus GG (LGG) was conducted in order to evaluate its efficacy for children with functional abdominal pain. They enrolled 141 children (aged 5-14 years) who were treated for 8 weeks and demonstarted that LGG significantly reduced both frequency and severity of abdominal pain 
compared to placebo in IBS patients [97]. By the same way, other authors observed a decreased frequency of abdominal pain yet not pain severity in children treated with LGG [98-99].

On the other hand, a randomized, double-blind, placebo-controlled trial carried out on a total of 64 children showed that LGG was equally effective than placebo in improving IBS symptoms but could only help relieve perceived abdominal distention. In this study, children enrolled were randomized to receive either 1 capsule of LGG at a concentration of 1010 bacteria (twice per day) or a placebo for 6 weeks. No significantly differences between the two groups are observed either in terms of abdominal pain relief or other gastrointestinal symptoms [100]. In conclusion, no substantial evidence is available about the efficacy of probiotic supplementation in children with IBS.

\section{Dietary interventions}

Self-perceived food intolerance is common among children with IBS [101] and most of the children complaint of worsening of symptoms following meals [102]. Moreover, dietary interventions are generally better accepted by families, compared to pharmacological ones, due to the functional nature of the disease. However, there is a lack of evidence supporting their use in children with FGIDs [7] and unfortunately most of the available evidence is aged. Fatty foods and foods rich in carbohydrates have been recognized by paediatric patients as possible causative factors for symptoms onset [103]. Nevertheless, avoidance of a culprit food has generally limited efficacy on improvement of symptoms.

Lactose free diet was not proved to be useful in children with recurrent abdominal pain $[4,5]$, even though, sometimes IBS may mimic lactose intolerance [104]. Evidences supporting the supplementation with fibers in IBS patients are limited, especially in children. Data from a systematic review including 4 pediatric studies reported that dietary fiber supplements are not effective in treating children with functional abdominal pain, compared to placebo [105]. Little benefit is reported only with psyllium hydrophilic mucilloid in adults with IBS [28].

Conversely, growing evidence indicates that a diet with low fermentable oligosaccharides, disaccharides, monosaccharides and polyols (FODMAPs) may ameliorate IBS symptoms both in adults and in 
children [106, 107]. Fermentable carbohydrates, such as lactose and fructose, are generally poorly absorbed, and they can osmotically induce water retention and, consequently, small bowel distention. The osmotic effect has been objectively demonstrated in adults by using abdominal magnetic resonance evaluation after FODMAPs administration [108]. Moreover, FODMAPs promote a fermentation of colonic bacteria, leading to gas production [109]. Furthermore, they can modify the gut microflora [110]: a decreasing of short chain fatty acids has been reported in patient on a low FODMAPs diet, and this can affect the intestinal motility [111]. Low-FODMAP diet is characterized by two phases: strict reduction of all dietary FODMAPs followed by reintroduction of specific FODMAPs according to patients' tolerance. A randomized, crossover, double blind prospective study conducted on 52 children aged 7-17 years demonstrated that low FODMAPs diet appears to significantly mitigate GI symptoms in patients with IBS in 48 hours, comparing to typical American childhood diet and patient usual diet [112]. Nevertheless only 33 children completed both arms of the crossover trial. In the same study, the stool analysis demonstrated that children who responded to diet exhibited a specific microbiome composition with an increased abundance of bacterioides, ruminococcus and faecalibacterium prausnitzii and an increased capability of hydrolyzing sugar molecules at baseline. The Authors concluded that those factors could be used as indicators of good response to FODMAP restrictive diet [113]. In adults, the maximal response on symptoms has been demonstrated after 7 days of low FODMAP diet [114]. Efficacy of the elimination phase has been fairly described in adults [99], though evidences regarding the reintroduction phase are poor. Based on expert's opinion, children who successfully responded to diet should be reintroduced with all foods within 6 weeks according to tolerance [100]. Possible risks related to long term low FODMAP diet could be the modification of intestinal microflora with reduction in beneficial bacteria $[115,110]$ and increased risk for disordered eating behaviors [116]. Moreover, it also may also lead to microelements deficiency such as iron, calcium and zinc iron, fibers, antioxidants and vitamins $[117,118]$.

Benefits of gluten-free diet on pain, bloating and stool consistency has been reported in non-coeliac adult patient with IBS [119]. No specific randomized controlled trials on gluten-free diet administration and re-challenge are available for children with IBS. However, gluten intolerance is commonly reported by parents of children with IBS symptoms [100]. Nevertheless, it has to be underlined that high levels of FODMAPs are contained in wheat, which could explain the usefulness of gluten-free diet in those patients [120]. 


\section{Biopsychosocial therapies}

Biopsychosocial therapies in paediatrics include mainly cognitive-behavioural techniques, psychosocial interventions, family therapy, hypnotherapy, yoga and guided imagery. They not only aim to directly effect on functional symptoms, but also to identify symptom triggers, impact on the child's ability to cope and recover and improve the child's mental health [121]. A meta-analysis including 6 studies conducted on 167 children with functional abdominal pain and IBS reported a beneficial effect on pain characteristics of cognitive behavioural therapy $[\mathrm{CBT}]$ in those patients, even though these studies exhibited methodological weaknesses, clinical heterogeneity and a small number of patients included [122]. A more recent Cochrane review analysing 10 interventional studies reported the utility of CBT in children with functional abdominal pain in the short term [3 months], without real benefit during the follow-up period [at 6 months and one year] [123]. However, no IBS children were included in the analysis. CBT is a generally well-accepted therapy for IBS in adults [123]. Its use has been promoted by the American Academy of Pediatrics as a useful tool to improve pain and disability in children in the short term [124].

Psychosocial intervention and family therapy aim at communicating information about the functional disorder to the patient and their families, in order to reassure them and let the patient figure out factors that may arouse symptoms, in order to increase children coping skills and avoid reinforcement of maladaptive behaviours $[125,126]$.

Hypnotherapy has recently become more popular for IBS treatment in adults and children. The hypnotic process is constituted of several steps, aiming at inducing general relaxation, teaching how to normalize visceral sensation and gut function [127]. When compared to other standard therapy [including education, dietary modification and pain medications], hypnotherapy resulted superior in reducing pain in children with functional abdominal pain and IBS [128]. Its effectiveness was confirmed during the follow up period, and in particular $85 \%$ and $68 \%$ of children were considered to be in clinical remission even after 1 and 5 years of follow-up respectively, compared to $25 \%$ and $20 \%$ of those receiving standard therapies [128, 129$]$. A further prospective randomized controlled trial conducted on 20 children with functional abdominal pain and IBS and 18 controls, reported a significant reduction of pain scores and pain related disabilities in those 
receiving hypnotherapy compared to controls [130]. Moreover, hypnotherapy was reported to be beneficial in reducing pain frequency and intensity in children with IBS or functional abdominal pain even if electronically delivered by using a compact disk [131].

Yoga has been considered as a behavioural intervention consisting in breathing and relaxation exercises and meditation, entailing the cultivation of physical and mental health [27]. A study conducted on 25 paediatric patients receiving one yoga live session and 4 weeks of a home instructional video reported a significant beneficial effect of this therapy in improving pain related disabilities and anxiety, with not a real effect on symptoms [132]. Conversely, another study including 20 children with functional abdominal pain and IBS aged 8 to 18 years reported a significant benefit on pain severity and frequency after receiving 10 live session of Hata yoga and also practicing it at home [133]. Similar findings have been reported in a more recent study conducted on 51 adolescents and young adults with IBS, practicing a 6-week twice per week Iyengar yoga program: adolescents practising yoga reported a significant improvement in physical disabilities compared to controls, while young adults practicing yoga reported a significant reduction of gastrointestinal symptoms with a related global improvement [134].

Guided imagery is a specific form of relaxation treatment that has been reported to be effective in reducing pain frequency in children with recurrent abdominal pain [135]. Its usefulness has been reported also in adult patients with IBS, resulting in symptoms and quality of life improvement [136]. However, no studies have been conducted in children with IBS.

\section{Conclusions}

IBS is a common and troublesome disorder in children with an increasing prevalence reported during the past two decades [1,2]. It has a significant impact on the lives of both affected children and their families and farther poses a significant burden on healthcare systems. A number of potential patho-physiological mechanisms have been described, but so far the exact underlying etiology of IBS is unclear. Rome IV diagnostic criteria allow a proper identification of IBS, avoiding useless investigations which should be used for selected cases to exclude other serious conditions that may present with similar features. Despite these 
undoubted diagnostic improvements, few potential therapeutic modalities have been tested in children and only a small number of them have shown some benefit (table 1). Indeed, most of the patho-physiological mechanisms described and treatment options are based on adult studies.

In conclusion, following a diagnosis of IBS no single available treatment has been shown to alter the natural history of this disorder and no therapy could be considered well-supported by the existing scientific literature. Hereafter, we hope that a better understanding of the pathogenetic mechanisms of the disease [motility of the digestive tract, intestinal microbiota, underlying genetic and epigenetic mechanisms, gastrointestinal signaling molecules and brain-gut axis] would facilitate the development of more effective therapy and would have a major positive impact on IBS patients, on their families and on health systems economies.

\section{References}

1. Rasquin A, Di Lorenzo C, Forbes D, et al. Childhood functional gastrointestinal disorders: child/adolescent. Gastroenterology. 2006;130[5]:1527-37

2. Korterink JJ, Diederen K, Benninga MA, Tabbers MM. Epidemiology of pediatric functional abdominal pain disorders: a meta-analysis. PLoS One 2015; 10: e0126982

3. Scarpato E, Quitadamo P, Roman E, et al. Functional Gastrointestinal Disorders in Children: A Survey on Clinical Approach in the Mediterranean Area. J Pediatr Gastroenterol Nutr. 2017;64[6]:e142-e14

4. Giannetti E, De'angelis G, Turco R, et al. Subtypes of Irritable Bowel Syndrome in Children: Prevalence at Diagnosis and at Follow-Up. J Pediatr. 2014 May;164[5]:1099-103

5. Langshaw AH, Rosen JM, Pensabene L, et al. Overlap between functional abdominal pain disorders and organic diseases in children Rev Gastroenterol Mex. 2018 Apr 2

6. Camilleri M. Peripheral mechanism in irritable bowel syndrome. N Engl J Med 2012;367:1626-35

7. Huertas-Ceballos A, Logan S, Bennett C, Macarthur C. Pharmacological interventions for recurrent abdominal pain (RAP) and irritable bowel syndrome (IBS) in childhood. Cochrane Database Syst Rev 2008 
8. Paul SP, Barnard P, Bigwood C, Candy DC. Challenges in management of irritable bowel syndrome in children. Indian Pediatr 2013;50:1137-43

9. Tougas G. The autonomic nervous system in functional bowel disorders. Gut 2000;47:78-80

10. Mayer EA, Collins SM. Evolving pathophysiologic models of functional gastrointestinal disorders. Gastroenterology 2002;122:2032-48

11. Ohman L, Simrén M. Pathogenesis of IBS: role of inflammation, immunity and neuroimmune interactions. Nat Rev Gastroenterol Hepatol 2010;7:163-73

12. Cremon C, Gargano L, Morselli-Labate AM, Santini D, Cogliandro RF, De Giorgio R, Stanghellini V, Corinaldesi R, Barbara G. Mucosal immune ac tivation in irritable bowel syndrome: gender-dependence and association with digestive symptoms. Am J Gastroenterol 2009;104:392-400

13. Piche T, Saint-Paul MC, Dainese R, Marine-Barjoan E, Iannelli A, Montoya ML, Peyron JF, Czerucka D, Cherikh F, Filippi J, Tran A, Hébuterne X. Mast cells and cellularity of the colonic mucosa correlated with fatigue and depression in irritable bowel syndrome. Gut 2008;57:468-73

14. Walker MM, Talley NJ, Prabhakar M, Pennaneach CJ, Aro P, Ronkainen J, Storskrubb T, Harmsen WS, Zinsmeister AR, Agreus L. Duodenal mastocytosis, eosinophilia and intraepithelial lymphocytosis as possible disease markers in the irritable bowel syndrome and functional dyspepsia. Aliment Pharmacol Ther 2009;29:765-73

15. Barbara G, Stanghellini V, De Giorgio R, Cremon C, Cottrell GS, Santini D, Pasquinelli G, Morselli-Labate AM, Grady EF, Bunnett NW, Collins SM, Corinaldesi R. Activated mast cells in proximity to colonic nerves correlate with abdominal pain in irritable bowel syndrome. Gastroenterology 2004;126:693-702

16. Guilarte M, Santos J, de Torres I, Alonso C, Vicario M, Ramos L, Martínez C, Casellas F, Saperas E, Malagelada JR. Diarrhoea-predominant IBS patients show mast cell activation and hyperplasia in the jejunum. Gut 2007;56:203-9

17. Lee KJ, Kim YB, Kim JH, Kwon HC, Kim DK, Cho SW. The alteration of enterochromaffin cell, mast cell, and lamina propria $\mathrm{T}$ lymphocyte numbers in irritable bowel syndrome and its relationship with psychological factors. J Gastroenterol Hepatol 2008;23:1689-94 
18. Barbara G, Wang B, Stanghellini V, de Giorgio R, Cremon C, Di Nardo G, Trevisani M, Campi B, Geppetti P, Tonini M, Bunnett NW, Grundy D, Corinaldesi R. Mast cell-dependent excitation of visceral-nociceptive sensory neurons in irritable bowel syndrome. Gastroenterology 2007;132:26-37

19. Di Nardo G, Barbara G, Cucchiara S, Cremon C, Shulman RJ, Isoldi S, Zecchi L, Drago L, Oliva S, Saulle R, Barbaro MR, Stronati L. Neuroimmune interactions at different intestinal sites are related to abdominal pain symptoms in children with IBS. Neurogastroenterol Motil. 2014;26(2):196-204

20. Shulman RJ, Eakin MN, Czyzewski DI, Jarrett M, Ou CN. Increased gastrointestinal permeability and gut inflammation in children with functional abdominal pain and irritable bowel syndrome. J Pediatr. 2008;153(5):646-50

21. Novick J, Miner P, Krause R, et al. A randomized, double-blind, placebo-controlled trial of tegaserod in female patients suffering from irritable bowel syndrome with constipation. Aliment Pharmacol Ther. 2002;16:1877-88

22. Hua MC, Chao HC, Yao TC, Lai MW, Huang JL; PATCH Study Group. Investigation of interleukin-10 promoter polymorphisms and interleukin-10 levels in children with irritable bowel syndrome. Gut Liver $2013 ; 7: 430-6$

23. Rees WD, Evans BK, Rhodes J. Treating irritable bowel syndrome with peppermint oil. Br Med J 19796;2[6194]:835-6

24. Grigoleit HG, Grigoleit P. Peppermint oil in irritable bowel syndrome. Phytomedicine 2005;12:601-6

25. Kline RM, Kline JJ, Di Palma J, Barbero GJ. Enteric-coated, pH-dependent peppermint oil capsules for the treatment of irritable bowel syndrome in children. J Pediatr. 2001;138[1]:125-8

26. Saps M, Miranda A. Gastrointestinal Pharmacology. Handb Exp Pharmacol. 2017;239:147-176. doi: 10.1007/164_2016_119. PMID: 28236087

27. Sandhu BK, Paul SP. Irritable bowel syndrome in children: pathogenesis, diagnosis and evidence-based treatment. World J Gastroenterol. 2014;20[20]:6013-23

28. Ford A, Talley N, Spiegel B, Foxx-Orenstein A, Schiller L, Quigley E. Effect of fibre, antispasmodics, and peppermint oil in the treatment of irritable bowel syndrome: systematic review and meta-analysis. Br Med J 2008;13[337]:a2313 
29. Chiou E, Nurko S. Management of functional abdominal pain and irritable bowel syndrome in children and adolescents. Expert Rev Gastroenterol Hepatol. 2010;4[3]:293-304

30. Delvaux M, Wingate D. Trimebutine: mechanism of action, effects on gastrointestinal function and clinical results. J Int Med Res 1997;25:225-46

31. Shannon S, Hollingsworth J, Cook I, Collins S [1989] Effect of trimebutine on postprandial colonic motor activity in healthy subjects and patients with irritable bowel syndrome. Neurogastroenterol Motil 1:9-14

32. Valori R, Shannon S, Reddy N, Daniel E, Collins S [1987] The action of trimebutine maleate on gastrointestinal motility is mediated by opiate receptors in human subjects. Gastroenterol Clin Biol 11:102B

33. Karabulut GS, Beşer OF, Erginöz E, Kutlu T, Cokuğraş FÇ, Erkan T. The Incidence of Irritable Bowel Syndrome in Children Using the Rome III Criteria and the Effect of Trimebutine Treatment. J Neurogastroenterol Motil 2013;19:90-9

34. Lesbros-Pantoflickova D, Michetti P, Fried M, Beglinger C, Blum A [2004] Meta-analysis: the treatment of irritable bowel syndrome. Aliment Pharmacol Ther 20:1253-69

35. Martınez-Vazquez M, Va’zquez-Elizondo G, Gonza'lez-Gonza’lez J, Gutie'rrez-Udave R, MaldonadoGarza H, Bosques-Padilla F [2012] Effect of antispasmodic agents, alone or in combination, in the treatment of irritable bowel syndrome: systematic review and meta-analysis. Rev Gastroenterol Mex 77:82_ 90

36. Darvish-Damavandi M, Nikfar S, Abdollahi M. A systematic review of efficacy and tolerability of mebeverine in irritable bowel syndrome. World J Gastroenterol 2010;16:547-53

37. Pourmoghaddas Z, Saneian H, Roohafza H, Gholamrezaei A. Mebeverine for pediatric functional abdominal pain: A randomized, placebo-controlled trial. Biomed Res Int. 2014;2014

38. Rahman M, Ahmed D, Mahmuduzzaman M, Rahman M, Chowdhury M, Barua R, Ishaque S [2014] Comparative efficacy and safety of trimebutine versus mebeverine in the treatment of irritable bowel syndrome. Mymensingh Med J 23:105-13

39. Rexwinkel R, Zeevenhooven J, van Etten-Jamaludin FS, Benninga MA, Tabbers MM. Side effects associated with pharmacotherapy for pediatric irritable bowel syndrome and functional abdominal pain not otherwise specified: a systematic review. Expert Opin Drug Saf. 2019;18[2]:111-25 
40. Brandt L, Chey W, Foxx-Orenstein A, et al. An evidence-based position statement on the management of irritable bowel syndrome. Am J Gastroenterol 2009;104:1072

41. Ruepert L, Quartero AO, de Wit NJ, van der Heijden GJ, Rubin G, Muris JW [2011] Bulking agents, antispasmodics and antidepressants for the treatment of irritable bowel syndrome. Cochrane Database Syst Rev CD003460

42. Lee KJ. Pharmacologic Agents for Chronic Diarrhea. Intest Res. 2015;13[4]:306-12

43. Cann P, Read N, Holdsworth C, Barends D. Role of loperamide and placebo in management of irritable bowel syndrome [IBS]. Dig Dis Sci 1984;29:239-47

44. Lembo AJ, Lacy BE, Zuckerman MJ, et al. Eluxadoline for irritable bowel syndrome with diarrhea. N Engl J Med 2016;374:242-53

45. Steadman CJ, Talley NJ, Phillips SF, Zinsmeister AR. Selective 5-hydroxytryptamine type 3 receptor antagonism with ondan- setron as treatment for diarrhea-predominant irritable bowel syndrome: a pilot study. Mayo Clin Proc 1992;67:732-8

46. von der Ohe MR, Hanson RB, Camilleri M. Serotonergic me- diation of postprandial colonic tonic and phasic responses in humans. Gut 1994;35:536-41

47. Tong K, Nicandro JP, Shringarpure R, Chuang E, Chang L. A 9-year evaluation of temporal trends in alosetron postmarket- ing safety under the risk management program. Therap Adv Gastroenterol 2013;6:344-57

48. Shin A, Vijayvargiya P, Busciglio IA, et al. 841 Quantitative Assessment of Fecal Primary and Secondary Bile Acids in Health and Irritable Bowel Syndrome (IBS) With Diarrhea or Constipation. Gastroenterology 2013;5:49-50.

49. Chey WD, Kurlander J, Eswaran S. Irritable bowel syndrome: a clinical review. JAMA. 2015;313(9):949-58

50. Camilleri M. Bile Acid diarrhea: prevalence, pathogenesis, and therapy. Gut Liver. 2015;9(3):332-9

51. Halilbasic E, Claudel T, Trauner M. Bile acid transporters and regulatory nuclear receptors in the liver and beyond. J Hepatol. 2013;58:155-68

52. Pimentel M, Lembo A, Chey WD, et al. Rifaximin therapy for patients with irritable bowel syndrome without constipation. N Engl J Med 2011;364:22-32. 
53. Menees SB, Maneerattannaporn M, Kim HM, Chey WD. The ef- ficacy and safety of rifaximin for the irritable bowel syndrome: a systematic review and meta-analysis. Am J Gastroenterol 2012;107:28-35

54. Toledo TK, DiPalma JA. Antibiotics are effective in the treatment of bacterial overgrowth-related diarrhea. Am J Gastroenterol 2000;95:3644-5

55. Gasbarrini A, Lauritano EC, Gabrielli M, et al. Small intestinal bacterial overgrowth: diagnosis and treatment. Dig Dis 2007;25:237-40

56. Scarpellini E, Giorgio V, Gabrielli M, et al. A. Prevalence of small intestinal bacterial overgrowth in children with irritable bowel syndrome: a case-control study. J Pediatr 2009;155:416-20

57. Scarpellini E, Giorgio V, Gabrielli M, et al. Rifaximin treatment for small intestinal bacterial overgrowth in children with irritable bowel syndrome. Eur Rev Med Pharmacol Sci 2013;17:1314-20

58. Collins BS, Lin HC. Double-blind, placebo-controlled antibiotic treatment study of small intestinal bacterial overgrowth in children with chronic abdominal pain. J Pediatr Gastroenterol Nutr 2011;52:382-6

59. Liang J, Liu X, Pan M, et al. Blockade of Nav1.8 currents in nociceptive trigeminal neurons contributes to anti-trigeminovascular nociceptive effect of amitriptyline. Neuromolecular Med 2014;16:308-21

60. Thoua NM, Murray CD, Winchester WJ, et al. Amitriptyline modifies the visceral hypersensitivity response to acute stress in the irritable bowel syndrome. Aliment Pharmacol Ther 2009;29:552-60

61. Eisenach JC, Gebhart GF. Intrathecal amitriptyline acts as an N-methyl-D-aspartate receptor antagonist in the presence of inflammatory hyperalgesia in rats. Anesthesiology 1995;83:1046-54

62. Gray AM, Spencer PS, Sewell RD. The involvement of the opioidergic system in the antinociceptive mechanism of action of antidepressant compounds. Br J Pharmacol 1998;124:669-74

63. Liu J, Reid AR, Sawynok J. Spinal serotonin 5-HT7 and adenosine A1 receptors, as well as peripheral adenosine A1 receptors, are involved in antinociception by systemically administered amitriptyline. Eur J Pharmacol 2013;698:213-9

64. Rahimi R, Nikfar S, Rezaie A, AbdollahiM. Efficacy of tricyclic antidepressants in irritable bowel syndrome: a meta-analysis. World J Gastroenterol 2009;15:1548-53

65. Chao GQ, Zhang S. A meta-analysis of the therapeutic effects of amitriptyline for treating irritable bowel syndrome. Intern Med 2013;52:419-24 
66. Bahar RJ, Collins BS, Steinmetz B, Ament ME. Double-blind placebo-controlled trial of amitriptyline for the treatment of irritable bowel syndrome in adolescents. J Pediatr 2008;152:685-9

67. Saps M, Youssef N, Miranda A, et al. Multicenter, randomized, placebo-controlled trial of amitriptyline in children with functional gastrointestinal disorders. Gastroenterology 2009;137:1261-9

68. Teitelbaum JE, Arora R. Long-term efficacy of low-dose tricyclic antidepressants for children with functional gastrointestinal disorders. J Pediatr Gastroenterol Nutr 2011;53:260-4

69. Castro VM, Clements CC, Murphy SN, et al. QT interval and antidepressant use: a cross sectional study of electronic health records. BMJ 2013;346:\{288]

70. Olfson M, Marcus SC, Druss BG. Effects of Food and Drug Administration warnings on antidepressant use in a national sample. Arch Gen Psychiatry 2008;65:94-101

71. Santucci NR, Saps M, van Tilburg MA. New advances in the treatment of paediatric functional abdominal pain disorders. Lancet Gastroenterol Hepatol. 2020;5[3]:316-28

72. Pfannkuche HJ, Buhl T, Gamse R, et al. The properties of a new prokinetically active drug, SDZ HTF 919. Neurogastroenterol Motil 1995;7:280

73. Talley NJ. Serotoninergic neuroenteric modulators. Lancet. 2001; 358[9298]:2061-2068

74. Lacy BE, Yu S. Tegaserod: a new 5-HT4 agonist. J Clin Gastroenterol. 2002;34[1]:27-33

75. Nguyen A, Camilleri M, Kost LJ, et al. SDZ HTF 919 stimulates canine colonic motility and transit in vivo. J Pharmacol Exp Ther 1997;280:1270-6

76. Schikowski A, Thewissen M, Mathis C, et al. Serotonin type-4 receptors modulate the sensitivity of intramural mechanoreceptive afferents in the cat rectum. Neurogastroenterol Motil 2002;14:221-7

77. Muller Lissner SA, Fumagalli I, Bardhan KD, et al. Tegaserod, a 5- HT[4] receptor partial agonist, relieves symptoms in irritable bowel syndrome patients with abdominal pain, bloating and constipation. Aliment Pharmacol Ther. 2001;15:1655-66

78. Evans BW, Clark WK, Moore DJ, Whorwell PJ. Tegaserod for the treatment of irritable bowel syndrome and chronic constipation. Cochrane Database Syst Rev 2007; [4]: CD003960

79. Kim YS, Choi SC, Park JM, et al. The effect of tegaserod on symptoms and quality of life in Korean women with irritable bowel syndrome with constipation. J Neurogastroenterol Motil 2010;16:61-70 
80. Loughlin J, Quinn S, Rivero E, et al. Tegaserod and the risk of cardiovascular ischemic events: an observational cohort study. J Cardiovasc Pharmacol Ther 2010;15:151-7

81.FDA Joint Meeting of the Gastrointestinal Drugs Advisory Committee and Drug Safety and Risk Management Advisory Committee Briefing Document. https ://www.fda.gov/media/ 11901 3/download. Accessed August 19, 2019

82. Madia VN, Messore A, Saccoliti F, et al. Tegaserod for the Treatment of Irritable Bowel Syndrome. Antiinflamm Antiallergy Agents Med Chem. 2019 Sep 11

83. Olivia Liem, Hayat M Mousa, Marc A Benninga, Carlo Di Lorenzo. Tegaserod use in children: a singlecenter experience J Pediatr Gastroenterol Nutr 2008;46[1]:54-8

84. Quigley EM. Probiotics in functional gastrointestinal disorders: what are the facts? Curr Opin Pharmacol $2008 ; 8[6]: 704-8$

85. Salvatore S, Pensabene L, Borrelli O, et al. Mind the gut: probiotics in paediatric neurogastroenterology. Benef Microbes. 2018;10:1-16

86. Lin HC. Small intestinal bacterial overgrowth: a framework for understanding irritable bowel syndrome. JAMA 2004;292[7]:852-8

87. Carroll IM, Chang YH, Park J, Sartor RB, Ringel Y. Luminal and mucosal-associated intestinal microbiota in patients with diarrhea-predominant irritable bowel syndrome. Gut Pathog 2010;2[1]:19

88. Codling C, O’Mahony L, Shanahan F, Quigley EM, Marchesi JR. A molecular analysis of fecal and mucosal bacterial communities in irritable bowel syndrome. Dig Dis Sci 2010;55[2]:392-7

89. Rajilic-Stojanovic M, Biagi E, Heilig HG et al. Global and deep molecular analysis of microbiota signatures in fecal samples from patients with irritable bowel syndrome. Gastroenterology 2010;141[5]:1792-801

90. Rinttila T, Lyra A, Krogius-Kurikka L, Palva A. Real-time PCR analysis of enteric pathogens from fecal samples of irritable bowel syndrome subjects. Gut Pathog 2011;3[1]:6

91. Saulnier DM, Riehle K, Mistretta TA, et al. Gastrointestinal microbiome signatures of pediatric patients with irritable bowel syndrome. Gastroenterology 2011;141[5]:1782-91

92. Malinen E, Rinttila T, Kajander K, et al. Analysis of the fecal microbiota of irritable bowel syndrome patients and healthy controls with real-time PCR. Am J Gastroenterol 2005;100[2]:373-82 
93. Moayyedi P, Ford A, Talley N, et al. The efficacy of probiotics in the treatment of irritable bowel syndrome: a systematic review. Gut 2008;59[3]:325-32

94. Martens U, Enck P, Zieseniss E. Probiotic treatment of irritable bowel syndrome in children. Ger Med Sci 2010;8:Doc07

95. Guandalini S, Magazzù G, Chiaro A, et al. VSL\#3 improves symptoms in children with irritable bowel syndrome: a multicenter, randomized, placebo-controlled, double-blind, crossover study. J Pediatr Gastroenterol Nutr 2010;51:24-30

96. Francavilla R, Miniello V, Magistà AM, et al. A randomized controlled trial of Lactobacillus GG in children with functional abdominal pain. Pediatrics 2010;126:1445-52

97. Gawronska A, Dziechciarz P, Horvath A, Szajewska H. A randomized double-blind placebocontrolled trial of Lactobacillus GG for abdominal pain disorders in children. Aliment Pharmacol Ther 2007;25:177-184

98. Horvath A, Dziechciarz P, Szajewska H. Meta-analysis: Lactobacillus rhamnosus GG for abdominal painrelated functional gastrointestinal disorders in childhood. Aliment Pharmacol Ther 2011;33:1302-10

99. Bausserman M, Michail S. The use of Lactobacillus GG in irritable bowel syndrome in children: a doubleblind randomized control trial. J Pediatr 2005;147[2]:197-201

100. Chumpitazi BP, Weidler EM, Lu DY, et al. Self-perceived food intolerances are common and associated with clinical severity in childhood irritable bowel syndrome. J Acad Nutr Diet. 2016;116[9]:145864

101. Reed-Knight B, Squires M, Chitkara DK, van Tilburg MA. Adolescents with irritable bowel syndrome report increased eating-associated symptoms, changes in dietary composition, and altered eating behaviors: a pilot comparison study to healthy adolescents. Neurogastroenterol Motil. 2016;28[12]:1915-20

102. Huertas-Ceballos AA, Logan S, Bennett C, Macarthur C. Dietary interventions for recurrent abdominal pain [RAP] and irritable bowel syndrome [IBS] in childhood. Cochrane Database Syst Rev. 2009 Jan 21;[1]:CD003019

103. Khayyatzadeh SS, Kazemi-Bajestani SMR, Mirmousavi SJ et al. Dietary behaviors in relation to prevalence of irritable bowel syndrome in adolescent girls. J Gastroenterol Hepatol. 2018;33[2]:404-10 
104. Zhu Y, Zheng X, Cong Y, et al. Bloating and distention in irritable bowel syndrome: the role of gas production and visceral sensation after lactose ingestion in a population with lactase deficiency. Am J Gastroenterol. 2013;108[9]:1516-25

105. Newlove-Delgado TV, Martin AE, Abbott RA, et al. Dietary interventions for recurrent abdominal pain in childhood. Cochrane Database Syst Rev. 2017;3[3]:CD010972

106. Halmos EP, Power VA, Shepherd SJ, et al. A Diet Low in FODMAPs Reduces Symptoms of Irritable Bowel Syndrome. Gastroenterology. 2014; 146[1]:67-75

107. Pensabene L, Salvatore S, Turco R, et al. Low FODMAPs diet for functional abdominal pain disorders in children: critical review of current knowledge J Pediatr [Rio J]. 2019 Apr 24

108. Undseth R, Berstad A, Kløw NE, Arnljot K, Moi KS, Valeur J. Abnormal accumulation of intestinal fluid following ingestion of an unabsorbable carbohydrate in patients with irritable bowel syndrome: an MRI study. Neurogastroenterol Motil. 2014;26[12]:1686-93

109. Camilleri M, Ford AC. Irritable Bowel Syndrome: Pathophysiology and Current Therapeutic Approaches. Handb Exp Pharmacol. 2017;239:75-113

110. Halmos EP, Christophersen CT, Bird AR, Shepherd SJ, Gibson PR, Muir JG. Diets that differ in their FODMAP content alter the colonic luminal microenvironment. Gut. 2015;64[1]:93-100

111. Shepherd SJ, Parker FC, Muir JG, Gibson PR. Dietary triggers of abdominal symptoms in patients with irritable bowel syndrome: randomized placebo-controlled evidence. Clin Gastroenterol Hepatol. $2008 ; 6[7]: 765-71$

112. Chumpitazi BP, Cope JL, Hollister EB, et al. Randomised clinical trial: gut microbiome biomarkers are associated with clinical response to a low FODMAP diet in children with the irritable bowel syndrome. Aliment Pharmacol Ther. 2015;42[4]:418-27

113. Marsh A, Eslick EM, Eslick GD. Does a diet low in FODMAPs reduce symptoms associated with functional gastrointestinal disorders? A comprehensive systematic review and meta-analysis. Eur J Nutr. 2016;55[3]:897-906

114. Hill P, Muir JG, Gibson PR. Controversies and Recent Developments of the Low-FODMAP Diet. Gastroenterol Hepatol [N Y]. 2017;13[1]:36-45 
115. Staudacher HM, Lomer MC, Anderson JL, et al. Fermentable carbohydrate restriction reduces luminal bifidobacteria and gastrointestinal symptoms in patients with irritable bowel syndrome. J Nutr. 2012;142[8]:1510-18

116. Satherley R, Howard R, Higgs S. Disordered eating practices in gastrointestinal disorders. Appetite. 2015;84:240-50

117. Shivani Gupta, Gilda Schaffer \& Miguel Saps [2018]: Pediatric Irritable Bowel Syndrome and Other Functional Abdominal Pain Disorders: An Update of Non- Pharmacological Treatments, Expert Review of Gastroenterology \& Hepatology, DOI:10.1080/17474124.2018.1462699

118. Catassi G, Lionetti E, Gatti S, et al. The Low FODMAP Diet: Many Question Marks for a Catchy Acronym. Nutrients. 2017;16:9[3]

119. Biesiekierski JR, Newnham ED, Irving PM, et al. Gluten causes gastrointestinal symptoms in subjects without celiac disease: a double-blind randomized placebo-controlled trial. Am J Gastroenterol 106:508-14

120. Biesiekierski JR, Peters SL, Newnham ED, Rosella O, Muir JG, Gibson GR [2013] No effects of gluten in patients with self-reported non-celiac gluten sensitivity after dietary reduction offermentable, poorly absorbed, short-chain carbohydrates. Gastroenterology 145:320-28

121. Abbott RA, Martin AE, Newlove-Delgado TV, Bethel A, Thompson-Coon J, Whear R, Logan S. Psychosocial interventions for recurrent abdominal pain in childhood. Cochrane Database Syst Rev 2017; 1: CD010971

122. Huertas-Ceballos A, Logan S, Bennett C, Macarthur C. Psychosocial interventions for recurrent abdominal pain [RAP] and irritable bowel syndrome [IBS] in childhood. Cochrane Database Syst Rev 2008;1:CD003014

123. Ford AC, Quigley EM, Lacy BE, et al. Effect of antidepressants and psychological therapies, including hypnotherapy, in irritable bowel syndrome: systematic review and meta-analysis. Am J Gastroenterol. 2014;109[9]:1350-65

124. Di Lorenzo C, Colletti RB, Lehmann HP, et al; AAP Subcommittee; NASPGHAN Committee on Chronic Abdominal Pain. Chronic Abdominal Pain In Children: a Technical Report of the American Academy of Pediatrics and the North American Society for Pediatric Gastroenterology, Hepatology and Nutrition. J Pediatr Gastroenterol Nutr. 2005;40[3]:249-61 
125. Brent M, Lobato D, LeLeiko N. Psychological treatments for pediatric functional gastrointestinal disorders. J Pediatr Gastroenterol Nutr 2009;48[1]:13-21

126. Bursch B. Psychological/cognitive behavioral treatment of childhood functional abdominal pain and irritable bowel syndrome. J Pediatr Gastroenterol Nutr 2008;47[5]:706-7

127. Gonsalkorale WM, Whorwell PJ. Hypnotherapy in the treatment of irritable bowel syndrome. Eur J Gastroenterol Hepatol 2005;17:15-20

128. Vlieger AM, Menko-Frankenhuis C, Wolfkamp SC, Tromp E, Benninga MA. Hypnotherapy for children with functional abdominal pain or irritable bowel syndrome: a randomized controlled trial. Gastroenterology 2007;133:1430

129. Vlieger AM, Rutten JM, Govers AM, Fran $\neg$ kenhuis C, Benninga MA. Long-term follow-up of gutdirected hypnotherapy vs. standard care in children with functional abdominal pain or irritable bowel syndrome. Am J Gas $\neg$ troenterol. 2012;107[4]:627-31

130. Gulewitsch MD, Muller J, Hautzinger M, Schlarb AA. Brief hypnotherapeutic-behavioral intervention for functional abdominal pain and irritable bowel syndrome in childhood: a randomized controlled trial. Eur J Pediatr 2013; 172:1043-51

131. Rutten JMTM, Vlieger AM, Frankenhuis C, George EK, Groeneweg M, Norbruis OF, Tjon A Ten W, van Wering HM, Dijkgraaf MGW, Merkus MP, Benninga MA. Home-Based Hypnotherapy Selfexercises vs Individual Hypnotherapy With a Therapist for Treatment of Pediatric Irritable Bowel Syndrome, Functional Abdominal Pain, or Functional Abdominal Pain Syndrome: A Randomized Clinical Trial. JAMA Pediatr 2017; 171: 470-7

132. Kuttner L, Chambers CT,Hardial J, Israel DM, Jacobson K, Evans K. A randomized trial of yoga for adolescents with irritable bowel syndrome. Pain Res Manag. 2006;11[4]:217-23

133. Brands MM, Purperhart H, Deckers-Kocken JM. A pilot study of yoga treatment in children with functional abdominal pain and irritable bowel syndrome. Complement Ther Med. 2011;19[3]:109-1

134. Evans S, Lung KC, Seidman LC, Sternlieb B, Zeltzer LK, Tsao JC. Iyengar yoga for adolescents and young adults with irritablebowel syndrome. J Pediatr Gastroenterol Nutr. 2014;59[2]: 244-53 
135. Weydert JA, Shapiro DE, Acra SA, Monheim CJ, Chambers AS, Ball TM. Evaluation of guided imagery as treatment for recurrent abdominal pain in children: a randomized controlled trial. BMC Pediatr 2006;6:29

136. Boltin D, Sahar N, Gil E, et al. Gut-directed guided afective imagery as an adjunct to dietary modifcation in irritable bowel syndrome. J Health Psychol. 2015;20:712-20 